Nghiên cứu thử nghiệm đối chứng mù kép khác của Seiji Arihiro và CS trên 223 trẻ mắc bệnh đường ruột được chia thành 2 nhóm, nhóm bổ sung vitamin $D$ và nhóm bổ sung giả dược ( $n=108$ và $n=105$ theo thứ tự). Đối tượng nhận 500 đơn vị vitamin $D$ hàng ngày. Kết quả cho thấy nhóm bổ sung vitamin $\mathrm{D}$ có tỷ lệ mắc $\mathrm{NKHH}$ trên thấp hơn nhiều nhóm dùng giả dược ( $R R=0,59)$.

Rashmi Ranjan Das và CS nghiên cứu gộp 32 nghiên cứu để so sánh điều trị viêm phổi bằng vitamin $D$ và giả dược. Liều vitamin $D$ được sử dụng từ 1000 đơn vị đến 100.000 đơn vị cho trẻ dưới 5 tuổi, cách thức cung cấp vitamin $D$ có thể là liều đơn, hay 5 liều trong vòng 5 ngày, thời gian can thiệp là 1 năm. Kết quả không như trông đợi, việc sử dụng vitamin $D$ đường uống này không giúp nhiều cho trẻ dưới 5 tuổi mắc viêm phổi cấp.

\section{KẾT LUÂN}

Sau can thiệp nồng độ vitamin $D$ trung bình của nhóm can thiệp tăng thêm $5,54 \mathrm{ng} / \mathrm{ml}$ so với của $\mathrm{NC}$ là $1,38 \mathrm{ng} / \mathrm{ml}$, nồng độ vitamin $\mathrm{D}$ trung bình tăng thêm là $4,16 \mathrm{ng} / \mathrm{ml}$.

Can thiệp vitamin $D$ đã làm giảm tỷ lệ nhiễm khuẩn hô hấp ở nhóm can thiệp được 37,4\% so với nhóm chứng là $14,7 \%$, tỷ lệ nhiếm khuẩn hô hấp của nhóm can thiệp giảm hơn nhóm chứng là $22,7 \%$.

\section{TÀI LIỆ THAM KHẢO}

1. Nguyễn Xuân Hùng (2020), Thực trang suy dinh dưỡng thấp còi và hiệu quả can thiệp ở trẻ 12 đến
36 tháng tuổi tại huyện Kim Động, tỉnh Hưng Yên năm 2017", Luận án tiến sỹ Y học, Trường đại học Y Dược Hải Phòng.

2. Trân Quy. (2013), "Nhiễm khuẩn hô hấp cấp tính", Bài giảng nhi khoa tập 1 - Nhà xuất bản y học Hà Nội, trang 380-389.

3. Adebola E. Orimadegun et al (2020), "A systematic review and meta-analysis of sex defferences in morbidity and mortality of acute lower respiratory tract infections among african children", J Pediatr Rev, 8(2):65-78. doi:10.32598/jpr.8.2.65.

4. David A McAllister et al (2019), "Global, regional, and national estimates of pneumonia morbidity and mortality in children younger than 5 years between 2000 and 2015: a systematic analysis", Lancet Glob Health, 7(1):e47e57.doi:10.1016/S2214-109X(18)304408-X.

5. Giuseppe Saggesse et al (2018), "Vitamin D in pediatric age: consensus of the Italian Pediatric Society and the Italian Society of Preventive and social Pediatric, jointly with the Italian Federation of Pediatricians", Ital K Padiatr, 44:51. doi:10.1186/s13052-018-0488-7.

6. Giustina A và CS (2020), "Consensus statement from $2^{\text {nd }}$ International conference on controversies in vitamin D", Rev Endocr Metab Disord, 21(1):89116. doi: $10.1007 / \mathrm{s} 11154-019=09532-w$.

7. Heike A Bischoff - Ferrari et al (2006) "Estimation of optimal serum concentrations of 25 - hydroxyvitamin D for multiple health outcomes", Am J Clin Nutr. 84 (1): 18 - 28.

8. Holick F Michael (2007), "The vitamin D deficiency pandemic: Approach for diagnosis, treatment and prevention", Rev Endocr Metab Disord, 18(2):153-165. doi: $10.1007 / \mathrm{s} 11154-017$ 9424-1.

9. Holick MF and Tai C Chen (2008), "Vitamin D deficiency: a worldwide problem with health consequences", Am J Clin Nutr. 87 (4): 1080S - 1086S.

\title{
NHÂN 1 TRƯờ'NG HỢP THAI NGOÀI Ý MUỒN TRONG KHI SỬ DỤNG QUE CẤY TRÁNH THAI IMPLANON NXT®
}

\section{Nguyễn Ngọc Phương ${ }^{1}$, Hà Duy Tiến ${ }^{1}$, Nguyễn Thị Hồng Nhung ${ }^{1}$}

\section{TÓM TẮT}

Implanon $®$ là một nang chứa progestin tổng hợp (etonogestrel), được cấy dưới da với tác dụng tránh thai lâu dài có hồi phục. Trong hơn 10 năm có mặt tại thi trường Viêt Nam, Implanonß đang dân trở nên phổ biến vì tính tiện lợi và hiệu quả tránh thai rất cao. Các trường hợp mang thai ngoài ý muốn với que cây

${ }^{1}$ Bệnh viện Phụ Sản Trung Uơng

Chịu trách nhiệm chính: Nguyễn Ngọc Phương

Email: pika.hmu@gmail.com

Ngày nhận bài: 24.6.2021

Ngày phản biên khoa họ: 17.8.2021

Ngày duyệt bài: 25.8.2021 tránh thai etonogestrel là rất hiếm. Chúng tôi báo cáo 1 trường hợp có thai trong buồng tử cung trong khi đang tránh thai bằng que cấy Implanon NXTß. Bênh nhân 27 tuổi PARA 1001, cây que tránh thai từ tháng 4/2017. Sau cấy 8 tháng, bênh nhân được chẩn đoán lao phổi và điêu trị theo phác đồ 2RHZE/4RHE. 6 tháng sau khi bắt đâu điều trị, bệnh nhân phát hiện có thai 18 tuần. Que cấy vẫn nằm đúng vị trí và được tháo toàn ven sau đó 1 tuần. Bênh nhân tiếp tục theo dõi thai, đẻ thường đủ tháng với kết quả thăm khám sơ sinh bình thường. Qua đó minh họa như y văn đã đề cập, thuốc chống lao (với tác dụng cảm ứng enzym ở gan) có thể làm giảm tác dụng tránh thai của Implanon $\AA$.

Tư khóa: Thai ngoài ý muốn, que cấy tránh thai, Implanon, thuốc chống lao. 


\section{SUMMARY \\ UNINTENDED PREGNANCY WITH IMPLANTABLE SUBDERMAL CONTRACEPTIVE DEVICE IMPLANON: A CASE REPORT}

Implanon $\AA$, a synthetic subcutaneous progestin etonogestrel eluting capsule, was approved for use to provide long-acting reversible contraception (LARC). During more than 10 years of presence in Vietnam, Implanon $\AA$ becomes more and more popular because of its convenience and high birth control effect. The unintended pregnancy in patients using an etonogestrel contraceptive implant is very rare. We report 1 case of intrauterine pregnancy while using Implanon NXT\&. She is 27 years old, PARA 1001, contraceptive implanted since April 2017. After 8 months of implantation, she was diagnosed with pulmonary tuberculosis and treated according to the 2RHZE/4RHE regimen. 6 months after starting treatment, the patient was found to be 18 weeks pregnant. The implant remained in place and was removed intact 1 week later. The patient continued the pregnancy, delivered normally at full term with normal neonatal examination results. Thereby illustrating as mentioned in the literature, antitubercular medications (hepatic enzyme inducers) may reduce the contraceptive effect of Implanon $\AA$.

Keywords: unintended pregnancy, implantable subdermal contraceptive, Implanon, antitubercular medications.

\section{I. ĐĂT VẤN ĐỀ}

Có 4 loại progestin được sử dụng trong các biện pháp tránh thai bằng que cây bao gồm: levonorgestrel (Norplant ${ }^{\circledR}$, Jardelle $\AA$ ), nestorone (Elcometrine $®$ ), nomegestrol acetate (Uniplant $\AA$, Surplant $\AA$ ) và etonogestrel (Implanon $®$ ). Trong đó, Implanon $®$ (thế hêe mới là Implanon NXT $®$ hay Nexplanon $\circledR$ ) là loại que cấy mới nhất và được sử dung phổ biến nhất, chứa $68 \mathrm{mg}$ etonogestrel trong 1 nang nhựa dẻo không phân hủy. Được đưa ra thị trường từ năm 2006, que cấy Implanon NXT ® hiện nay có chiều dài $40 \mathrm{~mm}$, đường kính $2 \mathrm{~mm}$, được cây dưới da ở mặt trong cánh tay không thuận trong tuần đâu tiên của chu kỳ kinh nguyệt.

Sự giải phóng etonogestrel chậm, ổn định và giảm dần theo thời gian, gây ra: ngăn chă̆n sự rụng trứng trong ít nhất 30 tháng (bằng cách ức chế đỉnh LH). Đây là cơ chế tránh thai chính, ngoài ra thuốc cũng có tác dụng làm đặc chất nhầy cổ tử cung, ngăn sự xâm nhập của tinh trùng, làm teo niêm mạc tử cung, ngăn sự làm tổ và thay đổi nhu động của vòi tử cung

Implanon $®$ là một biện pháp tránh dài hạn có hồi phục với nhiều ưu điểm vượt trội so với các phương pháp tránh thai ngắn hạn khác (viên uống, thuốc tiêm tránh thai, ...): hiệu quả tránh thai rất cao (chỉ số Pearl 0,1), không phụ thuộc vào sự tuân thủ của người dùng, khả năng có thai lại ngay sau khi tháo que (sau 1 tuần không còn phát hiên etonogestrel trong huyết thanh và sự rụng trứng trở lại sau $3-4$ tuần.

Một số nghiên cứu trên thế giới ghi nhận các trường hợp tránh thai thất bại của Implanon $\AA$ (có thai trong hoặc ngoài buồng tử cung) [1-2] do đă̆t sai (kỹ thuât, thời điểm) hoăc tương tác thuốc - thuốc. Được đưa vào thị trường Việt Nam từ năm 2011, que cấy tránh thai

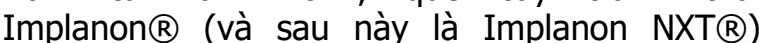
ngày càng trở nên phổ biến. Tuy nhiên cho đến nay chưa có nghiên cứu nào về tỷ lệ thất bại của biện pháp tránh thai này ở nước ta. Chúng tôi ghi nhận 1 trường hợp bênh nhân sử dụng que cây tránh thai Implanon NXT $囚$, có thai trong quá trình điều trị lao phổi.

\section{CA LÂM SÀNG}

Bênh nhân nữ 27 tuổi, PARA 1001: 01 lần đẻ thường năm 2015. Tiền sử khỏe manh, BMI 20,03 (chiều cao 1,58m, cân nặng 50kg).

Bệnh nhân được cấy que tránh thai Implanon NXT ngày 27/4/2017 tai Trung tâm tư vấn sức khỏe sinh sản - kế hoạch hóa gia đình, bệnh viện phụ sản Trung Ương. Que được cấy dưới da ở mặt trong tay trái (tay không thuân) vào tuần đầu tiên của chu kỳ kinh sau khi có kết quả khám phụ khoa bình thường và test thử thai âm tính. Sau cây que, bệnh nhân có rong kinh trên 10 ngày trong $3-4$ tháng đâu sau đó mất kinh.

Tháng 1/2018, bệnh nhân xuất hiện các triệu chứng hố hấp, đã được khám, chụp phim và làm các xét nghiệm thăm dò chẩn đoán xác định lao phổi. Bênh nhân được điêu trị lao theo phác đồ 2RHZE/4RHE (Isoniazid, Rifampicin, Pyrazinamid, Ethambutol). Trong quá trình điều trị, bệnh nhân vẫn vô kinh và không có ra máu bất thường.

Khi liệu trình điều trị lao sắp hết, bênh nhân thây bunng to lên kèm theo một số triệu chứng mệt mỏi, thèm ăn, khám phát hiện thai 18 tuần trong buồng tử cung. Kết quả siêu âm và các thăm dò cho thấy thai phát triển bình thường. Que cấy vẫn được sờ thấy và nằm đúng vị trí.

Sau 1 tuần suy nghĩ, bệnh nhân trở lại viện tháo que cấy ngày 27/6/2018 khi thai 19 tuần tuổi. Kiểm tra que cấy toàn vẹn, không thấy nứt vỡ.

Bênh nhân tiếp tục giữ thai, khám thai định kỳ, không có ra máu âm đạo trong suốt thai kỳ và chuyển da đẻ thường đủ tháng $(12 / 2018)$, Apgar $9-10$ điểm (ở 1 phút và 5 phút sau sinh) và theo dõi sơ sinh bình thường.

\section{BÀN LUÂN}

Đây là một trường hợp phụ nữ trong độ tuổi 
sinh đẻ, sử dụng que cây Implanon NXT® để tránh thai, tuy nhiên biện pháp thất bại dẫn đến có thai. Từ khi ra đời năm 1998, dù tỷ lệ tránh thai rất cao (trên 99\%) nhưng que cấy Implanon ${ }^{\circledR}$ cũng đã ghi nhận môt số báo cáo về các trường hợp có thai ngoài ý muốn. Thế hệ mới Implanon NXT $\AA$ (Nexplanon $\AA$ ) ngày càng hoàn thiện, tăng tỷ lệ tránh thai (thông qua việc giữ que cấy toàn vẹn đúng vị trí) tuy nhiên hiện tượng có thai ngoài ý muốn vẫn có thể xảy ra do một vài nguyên nhân khác nhau.

Tương tác thuốc là yếu tố quan trong ảnh hưởng đến tác dunng tránh thai của thuốc tránh thai nội tiết, đặc biệt là que cấy tránh thai. Quá trình chuyển hóa của các thuốc nội tiết này có vai trò của hệ thống enzym cytochrom P450 (CYP) trong gan. Do đó, các loại thuốc tạo ra các enzym của hệ thống CYP có thể làm tăng đào thải steroid (giảm nồng độ thuốc tránh thai trong máu), dẫn đến giảm khả năng tránh thai [3]. Một loạt các chất cảm ứng enzym manh gây ảnh hưởng này bao gồm: một số thuốc chống động kinh (carbamazepine, oxcarbazepine, phenytoin, phenobarbital, primidone, topiramate) [4], kháng sinh (rifampicin, rifabutin) [5], thuốc chống nấm (griseofulvin), thuốc ức chế protease (amprenavir, atazanavir, nelfinavir, lopinavir, saquinavir, ritonavir) và thuốc ức chế men sao chép ngược không nucleoside (efavirenz, nevirapine) [6].

Bệnh nhân của chúng tôi đã được điều trị lao bằng rifampicin-isoniazid trong khi sử dụng Implanon NXT R. Etonogestrel được chuyển hóa bởi hệ thống enzym CYP3A4 và rifampicin là chất cảm ứng, nhưng isoniazid gây ức chế hệ thống enzym này. Tác động cạnh tranh của rifampicin và isoniazid lên chuyển hóa của các thuốc chưa rõ ràng nhưng tác dụng cảm ứng enzym này làm giảm nồng độ etonogestrel trong huyết tương có thể giải thích cho sư tránh thai thất bai dẫn đến có thai ở bệnh nhẩn này. Các chuyên gia đều đồng thuận rằng nên kết hợp một biện pháp tránh thai rào cản khi đang sử dụng que cấy tránh thai với những trường hợp sử dụng các thuốc cảm ứng enzym trên, không chỉ trong khi dùng thuốc mà đến 28 ngày sau khi dừng thuốc. Những phụ nữ điều trị thuốc cảm ứng enzym này trong thời gian dài nên được tư vấn tháo que cây và sử dụng biện pháp tránh thai không nội tiết.

Ngoài ra, y văn cũng ghi nhận các trường hợp tránh thai thất bại dẫn đến có thai trong hoặc ngoài buồng tử cung với que cấy tránh thai Implanon do các nguyên nhân về kỹ thuật hoặc chỉ định.
Yếu tố hay gặp nhất dẫn đến thất bại trong tránh thai là do que nang etonogestrel không được cấy đúng cách. Nghiên cứu tại Úc năm 2005 cho thấy 40\% các trường hợp mang thai do cấy que không thành công (que cấy không được đưa vào hoặc đưa vào không đúng vị trí) [2]. Ngoài ra, sự toàn vẹn của nang cấy cũng được đề câp đến như mốt yếu tố nguy cơ làm thay đổi hiệu quả của thuốc khi nang không toàn vẹn, thay đổi diện tích bề mặt dấn đến giải phóng quá nhiều hoặc quá ít progestin [7]. Tuy nhiên, bênh nhân của chúng tôi không xảy ra các tình huống này do que cấy luôn được sờ thấy ở đúng vị trí và khi tháo thấy que hoàn toàn nguyên vẹn.

Thời điểm cấy que cũng rất quan trong, có thể ảnh hưởng đến tỷ lệ tránh thai thất bại. Khoảng $30 \%$ số ca có thai khi cấy que Implanon do người phụ nữ đã có thai từ trước hoặc cấy que muộn trong chu kỳ [2]. Việc loại trừ có thai trước khi cấy que bằng hỏi bệnh và các thăm khám lâm sàng, cận lâm sàng là thực sự cần thiết. Que cấy nên được cấy vào đầu chu kỳ kinh (tốt nhất là 5 ngày đẩu tiên của chu kỳ), ngoài thời gian trên cần áp dụng thêm biện pháp tránh thai rào chắn trong khoảng $1-2$ tuần.

Cũng như nhiều loại thuốc khác, trọng lượng cơ thể và chỉ số khối BMI của bệnh nhẩn cũng là một yếu tố cẩn được cân nhắc khi dùng phương pháp tránh thai nội tiết. Que cấy tránh thai Implanon với hàm lượng cố định cho tất cả phụ nữ, nồng độ etonogestrel trong huyết thanh tỷ lệ nghịch với chỉ số khối cơ thể (BMI). Do đó những phụ nữ thừa cân có nguy cơ mang thai cao hơn khi sử dụng que cấy tránh thai, đặc biệt là các trường hợp béo phì ( BMI trên 32,2) [8].

Có rất ít dữ liệu lâm sàng ở phụ nữ tiếp xúc với etonogestrel trong thời kỳ mang thai, nhưng không có tác dụng gây quái thai nào được báo cáo cho đến nay, đặc biệt là không có hiện tươnng nam hóa. Trong thai kỳ nên tháo que cấy tuy nhiên không thể tháo que (có thể do lạc chỗ) cũng không phải chỉ định đình chỉ thai [9].

Trong trường hợp tránh thai thất bai, cân xác định vị trí và sự phát triển của thai. Chửa ngoài cung là biến chứng hay gặp của các biện pháp tránh thai nội tiết. Cơ chế được cho là liển quan đến giảm co bóp cơ trơn của ống vòi tử cung [1].

Vô kinh là một tác dụng phụ hay gặp của que cấy tránh thai, do đó việc chẩn đoán sớm thai nghén khi cấy que đôi khi khó khăn nếu các triệu chứng nghén không rõ ràng, ảnh hưởng đến việc quyết đinh tiếp tục thai nghén hoăcc can thiểp nếu chửa ngoài tử cung. Ở trường hợp này, 
bệnh nhân phát hiện có thai khi thai đã 18 tuần tuổi, việc tiếp tục theo dõi thai đôi khi mang lại lo lắng, tuy nhiên không có bất thường nào được tím thấy trong suốt quá trình theo dõi.

Để tránh nguy cơ mang thai trong khi tránh thai bằng que cấy, các chuyên gia đều đồng thuận về quy trình nghiêm ngặt trong đào tạo bác sỹ thực hành, đảm bảo nang thuốc được đưa vào đúng vị trí. Thế hệ que cấy mới có chất cản quang giúp dễ phát hiện khi que cấy lạc chỗ. Ngoài ra, việc tư vấn cho người phụ nữ tự sờ que cấy và thông báo cho bác sỹ về sự có mặt của que cấy mối khi thăm khám ở tất cả các chuyên khoa là rất cần thiết.

\section{KẾT LUÂN}

Trường hợp bệnh nhân này là một minh họa cho việc tương tác thuốc của que cấy tránh thai với thuốc cảm ứng enzyme ở gan làm giảm tác dụng tránh thai, dẫn đến có thai ngoài ý muốn, chưa phát hiện thấy bất thường ở thai nhi cũng như các thăm khám sơ sinh. Cần thận trong với các tương tác này trong các chỉ định chẩn đoán và điều trị đặc biệt với các bệnh lý toàn thân.

\section{TÀI LIÊU THAM KHẢO}

1. R. Callahan, I. Yacobson, V. Halpern và cộng sứ (2015). Ectopic pregnancy with use of progestin-only injectables and contraceptive implants: a systematic review. Contraception, 92
(6), 514-522.

2. M. Harrison-Woolrych và R. Hill (2005). Unintended pregnancies with the etonogestrel implant (Implanon): a case series from postmarketing experience in Australia. Contraception, 71 (4), 306-308.

3. Organon Laboratories Ltd. Implanon $68 \mathrm{mg}$ implant for subdermal use: Summary of Product Characteristics (SPC). September 2009. Available at http://www.medicines.org.uk/ EMC/medicine/ 5382/SPC/Implanon+ 68mg+implant+for+ subdermal +use/ Accessed Jun 19, 2010.,

4. A. Lazorwitz, A. Davis, M. Swartz và công sự (2017). The effect of carbamazepine on etonogestrel concentrations in contraceptive implant users. Contraception, 95 (6), 571-577.

5. A. M. Baciewicz, C. R. Chrisman, C. K. Finch và cộng sự (2008). Update on rifampin and rifabutin drug interactions. Am J Med Sci, 335 (2), 126-136.

6. N. Leticee, J. P. Viard, A. Yamgnane và cộng sư (2012). Contraceptive failure of etonogestre implant in patients treated with antiretrovirals including efavirenz. Contraception, 85 (4), 425-427.

7. A. Elliman (2013). Removal of a fractured Nexplanon ${ }^{\circledR}$. J Fam Plann Reprod Health Care, 39 (1), 66-67.

8. L. M. Lopez, A. Bernholc, M. Chen và cộng sự (2016). Hormonal contraceptives for contraception in overweight or obese women. Cochrane Database Syst Rev, (8), Cd008452.

9. Centre de référence des agents tératogènes. Étonogestrel. 4 Mai 2021; Available from: http://lecrat.fr/articleSearchSaisie.php?recherche= etonogestrel.

\section{ĐÁNH GIÁ PHÂN LOẠI MỨC Độ ĐIỀU KIỀN LAO ĐộNG Ở LÁI XE KHÁCH ĐƯờ'NG DẦI}

\section{TÓM TẮT}

Mục tiêu: đánh giá mức độ điều kiện lao động ở lái xe khách đường dài. Phương pháp nghiên cứu: 200 nam lái xe khách đường dài tuyến cố định liên tỉnh với tuổi đời trung bình là 40,9 95,6 tuổi và tuổi nghề trung bình là $12,4 \pm 5,6$ năm đã tham gia nghiên cứu. Các lái xe được đo một số các yếu tố môi trường lao động, yếu tố tâm sinh lý lao động và đánh giá theo công văn số 2753/LĐTBXH-BHLĐ của Bộ Lao động - Thương binh và Xã hội. Kết quả: Điểm tổng hợp các yếu tố điều kiện lao động ở lái xe khách đường dài được đánh giá là 49,8 điểm; tương ứng với mức IV theo phân loai điều kiện lao động ở công văn

*Viện Sức khỏe nghề nghiệp và Môi trường

Chịu trách nhiệm chính: Nguyễn Thu Hà

Email: thuhayhld@gmail.com

Ngày nhận bài: 15.6 .2021

Ngày phản biên khoa họ: 10.8.2021

Ngày duyệt bài: 16.8.2021
Nguyễn Thu Hà*, Nguyễn Đức Sơn*

số 2753/LĐTBXH-BHLĐ của Bộ Lao động - Thương binh và Xã hội. Số các chỉ tiêu điều kiện lao động có mức xếp điểm $\geq 4$ trong tổng số các yếu tố điều kiện lao đông được đánh giá là 5 chỉ tiêu. Kết luân: việc thực hiện các giải pháp cải thiện điều kiện lào động cho lái xe để tăng cường khả năng làm việc và tránh các ảnh hưởng xấu tới sức khoẻ người lao động khi làm việc nhiều năm là rất cần thiết.

Từ khoá: Điều kiện lao động, lái xe khách đường dài, môi trường lao động, phân loại lao động, tâm sinh lý lao động

\section{SUMMARY \\ ASSESSMENT OF WORKING CONDITIONS IN LONG DISTANCE DRIVER}

Objectives:This study was carried out to assess the level of working conditions in long distance drivers. Methods: 200 male drivers with $40.9 \pm 5.6$ years of age and $12.4 \pm 5.6$ participated in this study. Drivers are measured some working environmental factors, psycho-physiological of work factors and 